\title{
Correction to: A Family Socialization Model of Transdiagnostic Risk for Psychopathology in Preschool Children
}

\author{
Mark Wade $^{1} \cdot$ Andre Plamondon $^{2} \cdot$ Jennifer M. Jenkins ${ }^{1}$
}

Published online: 29 March 2021

๑) Springer Science+Business Media, LLC, part of Springer Nature 2021

\section{Correction to: Research on Child and Adolescent Psychopathology \\ https://doi.org/10.1007/s10802-021-00789-x}

The original version of this article unfortunately contained a mistake. We noticed there is no mention of the shared firstauthorship by the first listed author (Wade) and the second listed author (Plamondon). To properly credit the authors, this change needs to be made. The below is the corresponding article note. Also, the email address of the author Andre Plamondon is also inserted. The original article has been corrected.

Publisher's Note Springer Nature remains neutral with regard to jurisdictional claims in published maps and institutional affiliations.

M. Wade and A. Plamondon are co-first authors

The original article can be found online at https://doi.org/10.1007/ s10802-021-00789-x

Mark Wade

m.wade@utoronto.ca; wadem2@gmail.com

Andre Plamondon

andre.plamondon@fse.ulaval.ca

1 Department of Applied Psychology and Human

Development, University of Toronto, 252 Bloor Street West,

ON M5S1V6 Toronto, Canada

2 Departement Des Fondements Et Pratiques en Education,

Laval University, Quebec, Canada 